\title{
Pembinaan Psikoedukasi Bagi Warga Binaan Di Lembaga Permasyarkatan Perempuan Kelas II Batam
}

\author{
Fredy Simanjuntak ${ }^{1}$, Desetina Harefa ${ }^{2}$, Rita Evimalinda ${ }^{3}$ Ester Lina Situmorang $^{4}$, Lidya \\ Dewi $\mathrm{S}^{5}$, Yefta Arisma ${ }^{6}$, Ceria7, Susilo Susanto ${ }^{8}$ \\ ${ }^{1,7,8}$ Prodi Teologi, STT REAL Batam \\ 2, 3, 4, 5, 6 Prodi PAK, STT REAL Batam \\ fredygrace@gmail.com
}

\begin{abstract}
This service aims to provide psycho-educational guidance to Christian female inmates at the Class II B Women's Prison in Batam, so that the inmates return to fully understand themselves as noble women. This study involved 35 Christian female inmates in the Class II B Women's Prison in Batam. The methods used are selfcompassion therapy, psychoeducation and woman discussion, as well as games for participants. Based on the results of the study, it can be concluded that there is an increase in the inmates' understanding of SelfCompassion so that after this therapy the inmates understand the recovery of their image and are able to accept themselves with their current conditions in prison. Furthermore, for psychoeducation of the role of women in ideals, participants have the tools to evaluate themselves with their roles so far and desire to experience transformation in themselves to become noble women in society.
\end{abstract}

Keywords: Empowerment, Psychoeducation, Inmates, Woman's Correctional society, Batam

\begin{abstract}
Abstrak
Pengabdian ini bertujuan untuk memberikan pembinaan psiko-edukasi pada warga binaan wanita kristen di Lapas Perempuan Kelas II B Batam, agar warga binaan kembali memahami dirinya secara utuh sebagai perempuan yang mulia. Penelitian ini melibatkan 35 warga binaan wanita beragama Kristen yang ada di Lapas Perempuan Kelas II B Batam. Metode yang digunakan adalah self-compassion therapy, psikoedukasi dan woman discussion, serta games bagi peserta. Berdasarkan hasil penelitian, dapat disimpulkan bahwa ada peningkatan pemahaman peserta warga binaan tentang Self-Compassion agar setelah terapi ini warga binaan memahami pemulihan akan gambar dirinya serta mampu menerima dirinya dengan kondisi saat ini di Lapas. Selanjutnya untuk psikoedukasi peran perempuan dalam cita-cita, peserta memiliki alat untuk mengevaluasi diri dengan perannya selama ini dan berkeinginan untuk mengalami transformasi pada diri sendiri untuk menjadi perempuan yang mulia di masyarakat.

Kata kunci: Pembinaan Transformatif, Warga Binaan, Lembaga Permasyarakatan, Batam
\end{abstract}

\section{PENDAHULUAN}

Sari mengemukakan bahwa penerimaan diri merupakan kesadaran individu tentang karakteristik yang dimilikinya baik secara pribadi dan kesediaan untuk menjalani kehidupan sesuai dengan karakteristik pribadi yang individu miliki. ${ }^{1}$ Sementara Ardilla \& Herdina mengemukakan bahwa seseorang yang dapat menerima diri adalah individu yang sudah mampu belajar untuk dapat hidup dengan dirinya sendiri. Kondisi awalnya, peserta sering merasa bersalah, tidak berharga dan belum bisa menerima kenyataan divonis sekian tahun sehingga harus menjalani hukuman. ${ }^{2}$ Terlebih dalam masyarakat yang dipengaruhi oleh budaya patriarki di Indonesia sering sekali sterotipe perempuan yang masuk dalam Lembaga permasyrakatan terkesan menyadang aib kaum perempuan. Perempuan sering hanya dipandang dari sisi fisiknya sehingga tampaknya perempuan dalam posisi di

\footnotetext{
${ }^{1}$ Luh Putu Shanti Kusumaningsih, "Penerimaan Diri Dan Kecemasan Terhadap Status Narapidana," Jurnal Psikologi Ilmiah 9, no. 3 (2017): 234-242.

${ }^{2}$ Fauziya Ardilla and Ike Herdiana, "Penerimaan Diri Pada Narapidana Wanita," Jurnal psikologi Kepribadian dan Sosial 2, no. 1 (2013): 1-7.
} 
bawah rehabilitasi Lembaga permasyrakatan menderita secar sosial dan sulit untuk mengekspresikan diri di tengah lingkungan sekitarnya. ${ }^{3}$

Warga binaan perempuan dan warga binaan laki-laki pada hakikatnya tidak memiliki perbedaan baik dalam hak maupun kewajiban, namun secara psikologis keadaan warga binaan perempuan jauh lebih rentan baik keadaan emosi, dan kesehatan mental dibandingkan dengan warga binaan laki-laki. Hal ini sesuai dengan penjelasan Butterfield dalam Gussak yang mengatakan warga binaan perempuan diyakini lebih rentan mengalami mental illness dibandingkan dengan warga bianaan laki-laki. ${ }^{4}$

Salah satu tujuan digelarnya program Pembinaan Psiko-edukasi di Lapas Lembaga Permasyarakatan Perempuan Kelas II B Batam ini adalah untuk mengembalikan citra warga binaan yang selama ini sering dihinggapi rasa cemas berinteraksi ketika kembali terjun ke masyarakat. Tim PkM STT Real Batam mengamati pentingnya para warga binaan mempunyai pola pikir (mindset). PkM ini lebih menekankan pada pembinaan moral dan spiritual pada warga binaan Lembaga Pemasyarakatan Perempuan bukan hanya untuk memberikan motivasi hidup yang kuat tetapi untuk menjadi manusia baru di dalam Kristus.

Model pembinaan Psiko-edukasi ini bertujuan untuk lebih banyak memberikan bekal bagi warga binaan baik saat berada di dalam lembaga permasyarakatan maupun dalam menyongsong kehidupan setelah selesai menjalani masa hukuman (bebas). Oleh karena itu, Tim PkM STT Real Batam sebelum terjun ke lapas melakukan observasi terlebih dahulu baik dengan para petugas lapas maupun kepada organisasi ataupun Lembaga pelayanan yang pernah melakukan pelayanan di LPP Kelas II B Batam. Oleh karena itu gagasan pembinaan psiko-edukasi ini merupakan program hasil observasi yang dianggap relevan dalam situasi dan kondisi warga binaan perempuan Kristen di LPP Kelas II B Batam. Sebagai pembinaan yang bertemakan "Menjadi manusia baru yang transformatif.

\section{Permasalahan Lapangan}

Keadaan psikologis berada di dalam Lembaga permasyrakatan membuat warga binaan memiliki cenderung tidak dapat menerima dirinya, sebagai dampaknya adalah permasalahanpermasalahan psikologis yang muncul seperti depresi, kecemasan, phobia dan anti-social personality. Seseorang warga binaan perempuan mengalami permasalahan psikologis sering kali karena mereka tidak dapat menerima keadaannya. Status baru yang disandangnya sebagai narapidana mempunyai stigma negatif di masyarakat sehingga membuat warga binaan banyak merasa cemas, terlebih depresi.

\section{Tujuan Kegiatan}

Tujuan pembinaan mental dan spiritual ini adalah untuk:

1. Membantu warga binaan memahami gambara diri mereka di dalam Kristus

2. Memberikan semangat dan motivasi bagi warga binaan dalam menjalani kehidupannya di lembaga permasyarakatan

3. Membuka paradigma berpikir warga binaan mengalami transformasi hidup yang berkualitas

\section{Manfaat kegiatan}

1. Menyiapkan warga binaan pemasyarakatan agar dapat berintegrasi secara sehat dengan masyarakat

2. Pemulihan kesatuan hubungan warga binaan pemasyarakatan dengan masyarakat.

3. Warga binaan pemasyarakatan dapat ikut serta perperan aktif dalam pembangunan serta hidup yang wajar sebagai warga negara yang baik dan bertanggung jawab, hal ini serupa dengan tujuan dari sitem pemasyarakatan yang berlaku di indonesia.

4. Meregulasi emosinya warga binaan sehingga tidak terus tenggelam dalam penyesalan masa lalu dan menyalahkan diri sendiri

${ }^{3}$ Ali Halidin, "Identitas Gender Dalam Perspektif Agama Kristen," Al-MAIYYAH : Media Transformasi Gender dalam Paradigma Sosial Keagamaan 10, no. 1 (2017): 25-44.

${ }^{4}$ David Gussak, "The Effects of Art Therapy on Male and Female Inmates: Advancing the Research

Base," The Arts in Psychotherapy 36, no. 1 (February 2009): 5-12,

https://linkinghub.elsevier.com/retrieve/pii/S0197455608000841. 
5. Mampu mengevaluasi perannya Kembali sebagai perempuan yang utuh baik secara personal, di dalam keluarga, maupun masyrakat.

Tahapan Kegiatan

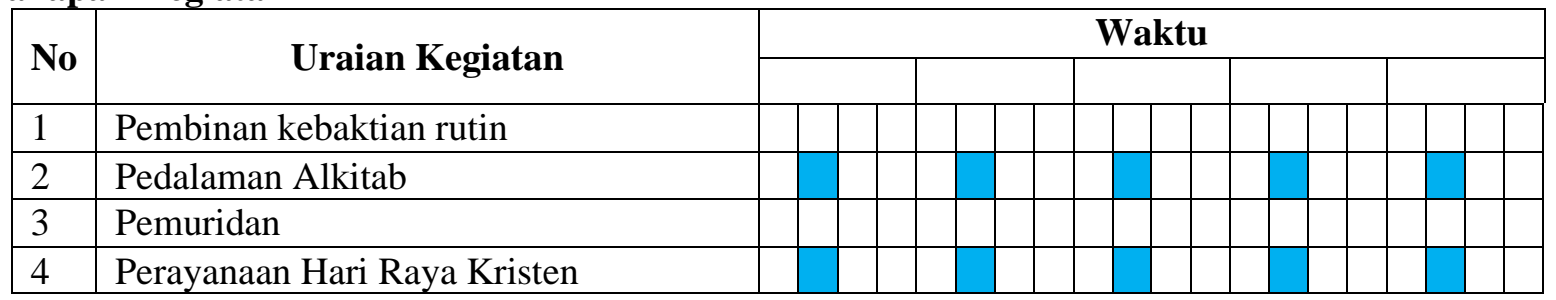

\section{Metode Penelitian}

Pengabdian ini dilakukan dengan menggunakan program Psikoedukasi yang diikuti oleh peserta warga binaan wanita Kristen di Lapas Perempuan Kelas II B Batam yang berjumlah 35 orang. Usia warga binaan yang mengikuti kegiatan pembinaan psikoedukasi rentangnya antara 21-50 tahun berjumlah 35 orang. Psikoedukasi yang diinginkan oleh peserta adalah pemahaman citra diri menjadi manusia baru. Kegiatan ini dilakukan dua kali dalam satu bulan yakni setiap minggu kedua di hari selasa. Pembinaan ini dilakukan pada tanggal 15 Oktober s/d 2 Februari 2020. Kegiatan PKM yang melibatkan beberapa prodi seperti Prodi Teologi \& PAK. Adapun dosen yang melakukan Pembinaan di Lapas tersebut adalah Fredy Simanjuntak, M. Th, Ester Lina Situmorang, M. Pd, Rita Evimalinda, M.Pd. K, Ardianto Lahagu, Lidya Dewi S, M.Pd. K, Rina Damanik, M. Pd, dan juga mahasisiwa antar prodi turut terlibat dala $\mathrm{m}$ berbagai kegiatan pembinaan.

\section{HASIL DAN PEMBAHASAN \\ Gambaran Lokasi Penelitian}

Lembaga Pemasyarakatan perempuan Kelas II Batam berdampingan dengan Lembaga pembinaan Khusus Anak Batam. Lembaga ini LPP II B Batam ini terletak di Jln. Jenderal Sudirman No.03 Sei Baloi - Batam. Lembaga Pemasyarakatan Anak Klas III Batam diresmikan pada tanggal 05 Agustus 2015 oleh Kepala Kantor Wilayah Kementerian Hukum dan Hak Asasi Manusia Kepulauan Riau dan Ibu DPRD TK II Batam dan Ka UPT sebatam,yg secara serentak di seluruh Indonesia,menjadi Lembaga Pembinaan Khusus Anak.Lembaga Pembinaan Khusus Anak Klas II Batam memiliki kapasitas 250 (dua ratus lima puluh )orang dengan luas tanah perkantoran $10.361 \mathrm{~m} 2$. Pada umumnya kasus-kasus kriminalitas warga binaan di Lembaga Permasyarakatan Perempuan Kelas II B Batam sebagian besar adalah pencurian, penipuan, penggelapan, pemalsuan, narkoba serta penculikan

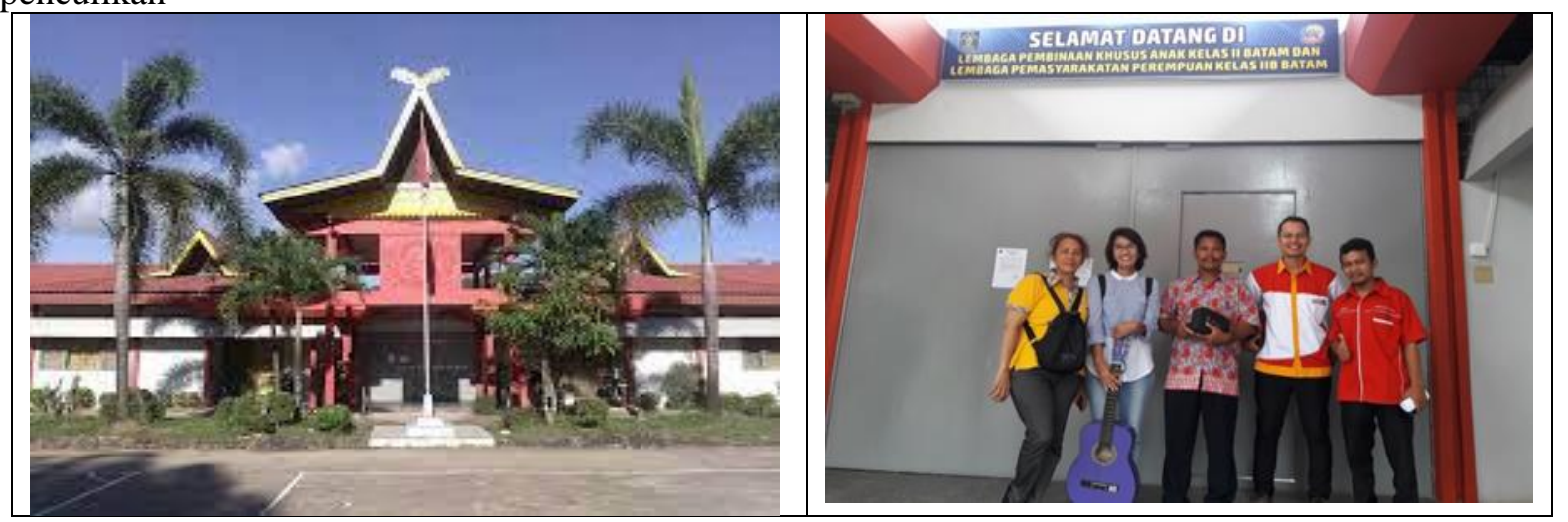

\section{Pola Pembinaan Psiko-Edukasi}

Sebagaimana disadari bahwa pembinaan narapidan di dalam lembaga pemasyarakatan bertujuan antara lain adalah reintegrasi untuk mongembalikan kesatuan hubungan hidup dan kehidupan antara terpidana dengan masyarakat luas melalui pembinaan narapidana yang kolaboratif, yaitu kerjasarna antara petugas terpidana dan masyarakat untuk mengurangi keterasingan (isolasi) 
terpidana dengan kehidupan masyarakat luas baik dalam arti fisik maupun nilai-nilai masyarakat. ${ }^{5}$ Istilah psikoedukasi seringkali juga diartikan sebagai mencakup keseluruhan aktivitas pendidikankonsultasi yang bersifat pelayanan kepada masyarakat (outreach activities). Gerakan ini adalah layanan lapangan berupa pendidikan dan konsultasi psikologis yang bertujuan preventifdevelopmental bagi kelompok-kelompok klien dari berbagai lapisan masyarakat serta di berbagai setting kehidupan. Psikoedukasi identik dengan pendidikan pribadi dan social. ${ }^{6}$ Berikut ini tahapantahao dalam melakukan pembinaan psikoedukasi sesuai dengan pemaparan Supratiknya. ${ }^{7}$

\section{Tahapan}

Persiapan, seorang pembina perlu melakukan persiapan pribadi. Khususnya, dia perlu merefleksikan pandangan hidup, nilai-nilai hidup, aneka kebutuhan, keyakinan teoretis, pilihan metode atau pendekatan, dan ketrampilan pribadinya. Apakah semua itu sesuai dan memadai sehingga menunjang

dalam membantu warga binaan memecahkan masalahnya? Contohnya, apakah sebagai calon pembina pandanganku tentang masalah dalam kehidupan wajar dan realistik belaka, atau cenderung ekstrem yaitu sebagai hukuman bahkan kutukan yang berasal dari Tuhan?

\section{Membangun Hubungan}

Sesudah merasa siap, pembina bisa segera masuk ke tahap membangun relasi konsultasi dengan warga binaan. Langkah- langkah yang segera perlu dikerjakan pada tahap ini adalah mendengarkan masalah yang dikemukakan oleh warga binaan serta merumuskan "aturan main" yang harus disepakati bersama warga binaan sebelum melakukan tindakan apa pun lebih lanjut. Aturan main yang dimaksud khususnya mencakup hal-hal yang diatur dalam kode etik profesi psikolog, seperti pentingnya warga binaan membuka diri secara terus terang kepada pembina di satu pihak dan kewajiban pembina untuk merahasiakan semua ungkapan warga binaan di pihak lain, dan sebagainya.

\section{Pengumpulan Informasi}

Sesudah dicapai kesepakatan kerja sama, Pembina perlu terlebih dulu mengumpulkan informasi tambahan untuk mendapatkan pemahaman yang lebih jelas dan mendalam tentang masalah yang dikemukakan oleh warga binaan. Informasi ini harus objektif.

\section{Problem-solving}

Merumuskan dan memilih solusi alternatif. Berdasarkan analisis dan sintesis dari seluruh informasi yang berhasil dikumpulkan dan akhirnya dirumuskan dalam goal statements, Pembina dan warga binaan bersama-sama melakukan problem-solving yaitu ber usaha merumuskan berbagai alternatif solusi beserta aneka konsekuensi termasuk kelebihan dan kekurangan dari masing-masing alternatif solusi yang berhasil ditemukan. Proses pemecahan masalah ini bisa dilakukan lewat proses brainstorming alias curah pendapat dan analisis SWOT (Strengths alias kekuat an, Weaknesses alias kelemahan, Opportunities alias peluang, dan Threats alias ancamannya).

\section{Implementasi.}

${ }^{5}$ Thomas Sunaryo, "Perpustakaan Penjara," Majalah Bahana (Jakarta, 1983).26

${ }^{6}$ A Supratiknya, Merancang Program Dan Modul Psikoedukasi, Yogyakarta: Universitas Sanata Dharma (Yogyakarta: Universitas Sanata Dharma, 2011), https://repository.usd.ac.id/12880/1/2011 Merancang Program dan Modul Psikoedukasi Edisi Revisi.pdf.30-32

${ }^{7}$ Ibid. 
Semua strategi dan langkah-langkah dalam rangka pemecahan masalah itu kini perlu dilaksanakan sesuai jadwal yang telah ditetapkan.

\section{Evaluasi}

Evaluasi formatif atau monitoring atas berbagai tahapan kegiatan. Perlu tidak nya dilakukan perbaikan-penyesuaian dan penambahan langkah-langkah baru bisa diketahui berdasarkan hasil monitoring ini. Jika semua ber- jalan efektif seperti direncanakan, akhir nya perlu dilakukan evaluasi sumatif atau final dalam rangka menilai tingkat keberhasilan penca- paian hasil akhir serta aneka dampak yang diharapkan dari seluruh kegiatan yang direncanakan.

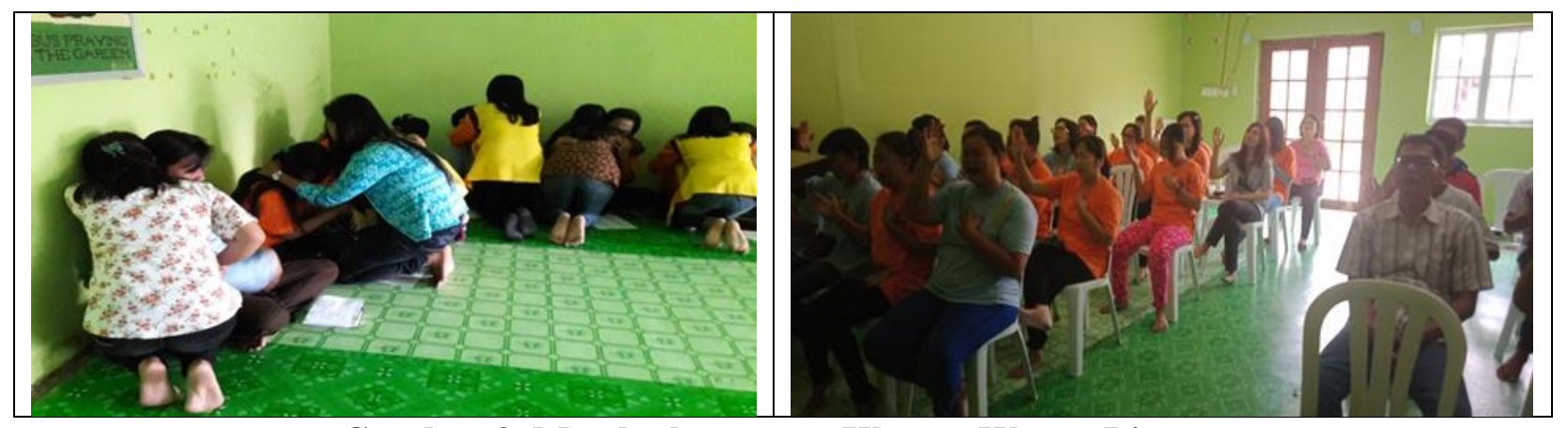

Gambar 3. Mendoakan secaa Khusus Warga Binaan

Sebelum dibagi dalam group pembinaan, kegiatan biasanya diawali dengan ibadah Bersama yang dilanjutkan dengan Sesi doa khusus bagi warga binaan. Dalam gambar 3 tampak para dosen dan mahasiswa terlibat mendoakan para warga binaan pribadi lepas pribadi. Hal yang khas selain pembinaan adalah sesi doa. Fredy Simanjuntak mengatakan dalam Alkitab, doa adalah renungan yang mencakup semua sikap roh manusia dalam pendekatannya kepada Tuhan. Orang Kristen mengabdi kepada Tuhan jika dia menyembah, mengakui, memuji, dan memohon kepada-Nya dalam doa. Doa sebagai perbuatan tertinggi yang dapat dilakukan oleh roh manusia juga dapat dilihat sebagai persekutuan dengan Tuhan, selama penekanan diberikan pada inisiatif ilahi. Seseorang berdoa karena Tuhan telah menjamah rohnya. ${ }^{8}$

Selain pembinaan juga sesekali diadakan program pengajaran supaya warga binaan semakin memahami prinsip-prinsip ajaran Kristus dalam Alkitab. Sebagaimana Latif meyakini pengajaran berperan penting dalam menyadarkan orang akan dosa sehingga hatinya dimampukan untuk mengalami sukacita oleh Firman yang memerdekakan. ${ }^{9}$

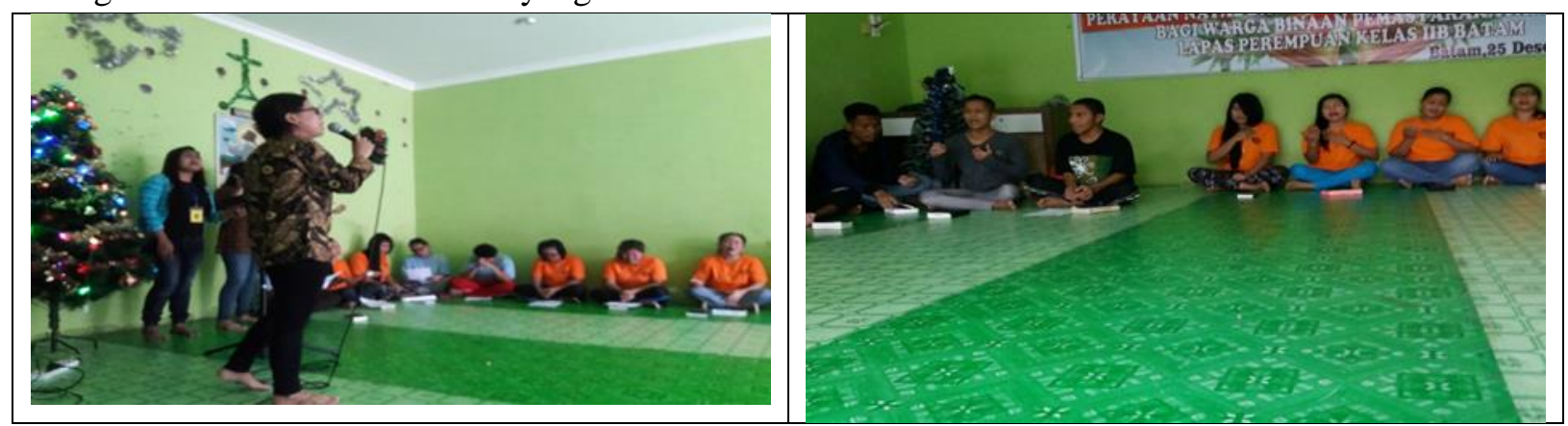

Gambar 2. Suasana Ibadah Bersama warga Binaan

${ }^{8}$ Fredy Simanjuntak, "Mission Driven Prayer," in KIngdom Economy and Mission, 2018, 105-112, https://doi.org/10.31219/osf.io/znef2.

9 Helen Farida Latif, "Pengaruh Pengajaran Dan Persekutuan Terhadap Tingkat Pertumbuhan Rohani Anak Dan Remaja," EPIGRAPHE 1, No. 1 (2017): 119-138.121 
Pembinaan juga bersifat kekeluargaan. Pada dasarnya seorang warga binaan pemasyarakatan sangat membutuhkan perhatian, khususnya perhatian dari keluarga maupun kerabat terdekat serta orang-orang yang ada disekitar oleh karena itu pembinaan yang dilakukan sedapat mungkin dilakukan dalam suasana keluarga. Pembinaan yang dilakukan sebenarnya selain dari upaya untuk memulihkan keadaan warga binaan secara psikologis tetapi sekaligus sebagai bentuk perhatian dan kasih sebagai saudara di dalam Kristus dengan pndekatan yang informal tanpa harus kehilangan suasana kekeluargaan.

Dengan diberikannya materi pembinaan psiko-edukasi ini, warga binaan menjadi terbuka dan mampu mengatur dan mengevaluasi sikap, pemikiran dan perasaan mereka sehingga mereka mulai tampil memiliki keyakinan yang kokoh akan citra diri mereka sebagai ciptaan Tuhan.

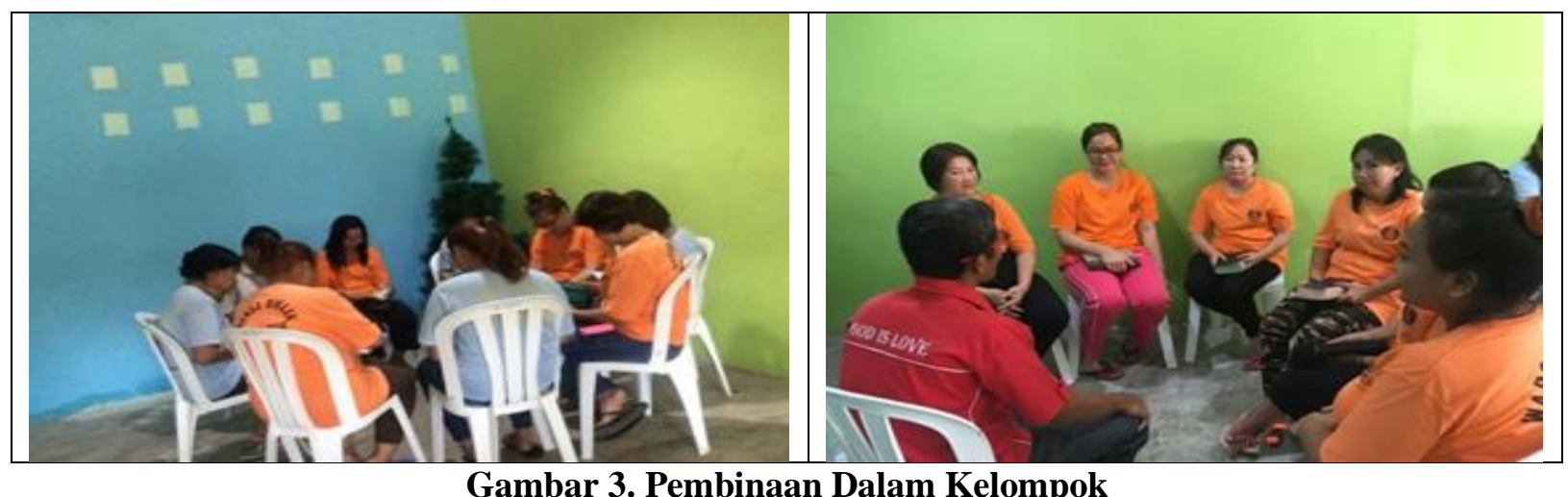

\section{SIMPULAN}

Kegiatan pengabdian psikoedukasi tetang self compassion untuk warga binaan perempuan agama Kristen di LPP Kelas II B Batam dapat terlaksana dengan baik. Adapun hasilnya menunjukkan bahwa terdapat peningkatan penerimaan diri peserta narapidana tentang citra diri sehingga setelah dilakukan terapi ini warga binaan tampak lebih bersemangat dan lebih menerima kondisinya yang sekarang berada di Lapas. Selanjutnya untuk psikoedukasi perempuan yang ideal dalam masyarakat menjadikan warga binaan memiliki instrument untuk mengevaluasi diri terkait atas kondisi psikologis yang mereka alami selama dalam pusat rehabilitasi. Kondisi spiritual yang terlihat dari warga binaan adalah perubahan dari kondisi kejiwaan yang mereka tunjukkan setelah pembinaan yang terusmenerus, keceriaan daan sukacita mereka meluap-luap dan begitu antusias. Bahkan beberapa diantara mereka memberikan testimony rasa syukur mereka diinjinkan Tuhan berada dalam lapas adalah merupakan proses didikan Tuhan untuk tujuan yang lebih mulia, Sebagian besar dari warga binaan menemukan atmosfir kehidupan baru yang penuh makna yang terlihat dari cara mereka berinteraksi satu sama lain baik kepada sesama warga binaan maupun kepada para pembina rohani maupun para petugas Pembina di lapas. Adapun saran yang dapat diberikan pada pihak Lapas kiranya pembinaan seperti ini dapat dilanjutkan di waktu-waktu yang akan dating untuk mentransformasi mental dan spiritual warga binaan di LPP Kelas II Batam. pada warga binaan begitu antusias sekali dengan program pembinaan psikoedukasi ini terbukti diikuti oleh warga binaan secara berkala.

\section{DAFTAR PUSTAKA}

Ardilla, Fauziya, and Ike Herdiana. "Penerimaan Diri Pada Narapidana Wanita." Jurnal psikologi Kepribadian dan Sosial 2, no. 1 (2013): 1-7.

Gussak, David. "The Effects of Art Therapy on Male and Female Inmates: Advancing the

Research Base." The Arts in Psychotherapy 36, no. 1 (February 2009): 5-12.

https://linkinghub.elsevier.com/retrieve/pii/S0197455608000841.

Halidin, Ali. "Identitas Gender Dalam Perspektif Agama Kristen." Al-MAIYYAH : Media

Transformasi Gender dalam Paradigma Sosial Keagamaan 10, no. 1 (2017): 25-44.

Kusumaningsih, Luh Putu Shanti. "Penerimaan Diri Dan Kecemasan Terhadap Status

Narapidana." Jurnal Psikologi Ilmiah 9, no. 3 (2017): 234-242.

Latif, Helen Farida. "Pengaruh Pengajaran Dan Persekutuan Terhadap Tingkat Pertumbuhan 
Rohani Anak Dan Remaja." EPIGRAPHE: Jurnal Teologi dan Pelayanan Kristiani 1, no. 1 (2017): 119-138.

Simanjuntak, Fredy. "Mission Driven Prayer." In KIngdom Economy and Mission, 105-112, 2018. https://doi.org/10.31219/osf.io/znef2.

Sunaryo, Thomas. "Perpustakaan Penjara." Majalah Bahana. Jakarta, 1983.

Supratiknya, A. Merancang Program Dan Modul Psikoedukasi. Yogyakarta: Universitas

Sanata Dharma. Yogyakarta: Universitas Sanata Dharma, 2011.

https://repository.usd.ac.id/12880/1/2011 Merancang Program dan Modul Psikoedukasi

Edisi Revisi.pdf. 